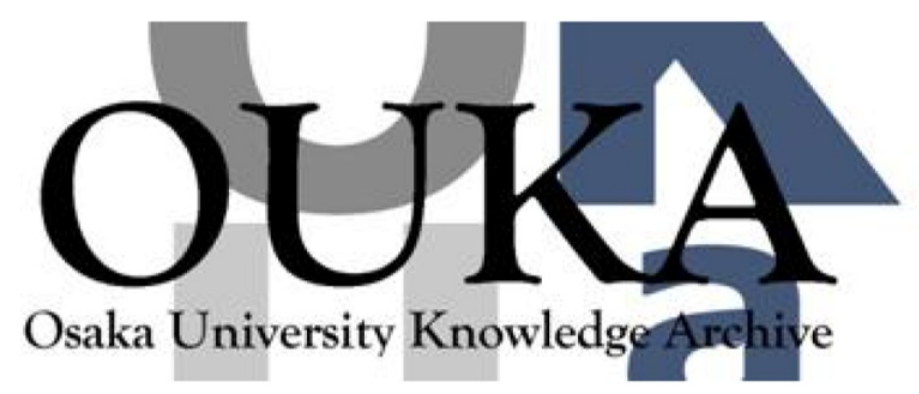

\begin{tabular}{|c|c|}
\hline Title & $\begin{array}{l}\text { Ti K } \alpha \text { radiography of Cu-doped plastic } \\
\text { microshell implosions via spherically bent } \\
\text { crystal imaging }\end{array}$ \\
\hline Author (s) & King, J. A. ; Akli, K.; Zhang, B. et al. \\
\hline Citation & Applied Physics Letters. 86(19) p. 191501 \\
\hline Issue Date & $2005-05$ \\
\hline oaire:version & VoR \\
\hline URL & ht tps://hdl. handle. net/11094/2986 \\
\hline rights & \\
\hline Note & \\
\hline
\end{tabular}

Osaka University Knowledge Archive : OUKA

https://ir. Library. osaka-u. ac. jp/

Osaka University 


\title{
Ti $K \alpha$ radiography of Cu-doped plastic microshell implosions via spherically bent crystal imaging
}

\author{
J. A. King, ${ }^{a)}$ K. Akli, and B. Zhang \\ Department of Applied Sciences, University of California, Davis, Davis, California 95616 \\ R. R. Freeman \\ College of Mathematical and Physical Sciences, Ohio State University, Columbus, Ohio 43210
}

M. H. Key, C. D. Chen, S. P. Hatchett, J. A. Koch, A. J. MacKinnon, P. K. Patel, R. Snavely, and R. P. J. Town

Lawrence Livermore National Laboratory, Livermore, California 94550

M. Borghesi, L. Romagnani, and M. Zepf

The Queens University of Belfast, Belfast, Northern Ireland, BT7 1NN, United Kingdom

T. Cowan

Department of Physics, University of Nevada Reno, Reno, Nevada 89557

H. Habara, R. Kodama, and Y. Toyama

Institute of Laser Engineering, Osaka University, Osaka 565, Japan

S. Karsch

Max Planck Institute for Quantum Optics, D-85748 Garching, Germany

K. Lancaster, C. Murphy, and P. Norreys

Rutherford Appleton Laboratory, Chilton, Oxon, OX11 OQX, United Kingdom

R. Stephens

General Atomics, San Diego, California 92186

C. Stoeckl

Laboratory for Laser Energetics, University of Rochester, Rochester, New York 14623

(Received 1 June 2004; accepted 21 March 2005; published online 3 May 2005)

\begin{abstract}
We show that short pulse laser generated Ti $K \alpha$ radiation can be used effectively as a backlighter for radiographic imaging. This method of $\mathrm{x}$-ray radiography features high temporal and spatial resolution, high signal to noise ratio, and monochromatic imaging. We present here the Ti $K \alpha$ backlit images of six-beam driven spherical implosions of thin-walled $500-\mu \mathrm{m} \mathrm{Cu}$-doped deuterated plastic (CD) shells and of similar implosions with an included hollow gold cone. These radiographic results were used to define conditions for the diagnosis of fast ignition relevant electron transport within imploded Cu-doped coned CD shells. () 2005 American Institute of Physics. [DOI: $10.1063 / 1.1923178]$
\end{abstract}

Radiography using nanosecond pulses of thermally generated soft $\mathrm{x}$-ray emission from high temperature laserproduced plasmas was developed for pulsed ${ }^{1}$ and streaked ${ }^{2}$ backlighting of laser-driven implosions and observation of fluid instabilities. ${ }^{3}$ It is now an important diagnostic widely used to record hydrodynamic phenomena of all kinds in laser-driven targets. In typical state-of-the-art measurements, gated channel plate imagers give 50 to $100 \mathrm{ps}$ time resolution. With multikilojoule laser energy the sources are bright enough for radiography at photon energies approaching $10 \mathrm{keV}$, but are ineffective at higher photon energies due to rapidly decreasing brightness. ${ }^{4}$

We present a demonstration of radiography of an implosion using a nonthermal $K \alpha$ radiation source generated with a high-intensity ultrashort laser pulse. This technique gives more than a tenfold improvement in time resolution and readily achieves the brightness required for high-definition radiography. Conversion efficiency measurements with subjoule short pulse lasers and Monte Carlo modeling ${ }^{5}$ suggest

\footnotetext{
${ }^{a)}$ Electronic mail: king55@1lnl.gov
}

the source is scalable to $100 \mathrm{keV}$, giving a potential capability to penetrate up to $1000 \times$ more matter than thermal plasma radiography. The enhanced penetration promises to be vital for radiography of the more massive and dense implosions produced by the megajoule-class lasers and $Z$ pinches, which will be used to demonstrate thermonuclear ignition in inertial confinement fusion research.

The diagnostic was implemented using an 81-J, 800-fs, 1053-nm Nd:glass laser pulse. ${ }^{6}$ The beam was focused by an $f / 3$ off-axis parabolic mirror. An out-of-focus plane was chosen producing a $440 \times 750 \mu \mathrm{m}^{2}$ full width at half maximum (FWHM) elliptical spot on a $25-\mu$ m-thick Ti foil with an average intensity of $3.1 \times 10^{16} \mathrm{~W} / \mathrm{cm}^{2}$. The laser interacted with the foil to produce an extended backlighting source of $K \alpha$ x rays. ${ }^{7}$ This source was located $4 \mathrm{~mm}$ from the target and irradiated on its side opposite the target. The target was a 500- $\mu \mathrm{m}$-diam, 7- $\mu \mathrm{m}$-thick $\mathrm{Cu}$-doped deuterated (CD) polymer shell $\mathrm{Cu}$ doped at 0.7 at. \%. Some targets included an inserted hollow gold cone used as the conduit for the ignitor beam in fast ignition studies. ${ }^{8}$ The implosion was produced with six $10.8-\mathrm{cm}$-diam. orthogonal drive beams 

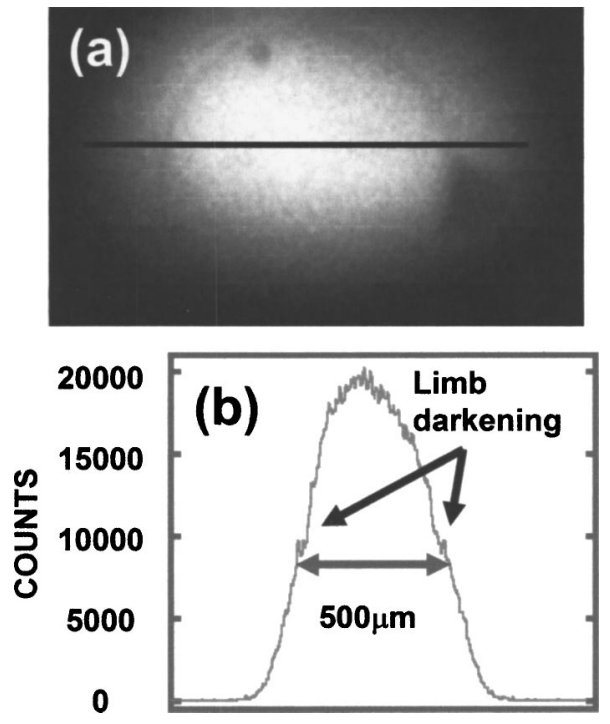

FIG. 1. (a) $K \alpha$ radiographic image of an unimploded $500-\mu \mathrm{m}$ polymer shell. (b) The horizontal line out [indicated by the horizontal line through the image 1(a)] reveals an average intensity of 18000 counts.

each delivering 157-J, 1-ns Gaussian pulses at $1053 \mathrm{~nm}$ and focused at $f / 2.5$ with their marginal rays tangential to the shell. A 1.6-cm aperture $\mathrm{SiO}_{2} 2023$ quartz crystal bent to a radius of $38 \mathrm{~cm}$ and operating at $1.0^{\circ}$ off normal incidence imaged a plane centered in the backlit implosion. It produced a $7.9 \times$ magnified image onto a Princeton Instruments TEK1024 $\times 1024$ DBT3, 1 sq in., $1024 \times 1024$ pixel chargecoupled device (CCD) internally cooled to $-30{ }^{\circ} \mathrm{C}$. Astigmatism and spherical aberration limited the theoretical spatial resolution of this image to $10 \mu \mathrm{m} .{ }^{9}$ At $7.9 \times$ magnification, a $10-\mu \mathrm{m}$ resolution corresponds to 3 pixels. The images have therefore been smoothed over $3 \times 3$ pixel areas without significant loss of information. This smoothed pixel limited resolution of $9.6 \mu \mathrm{m}$ convolved with the $10-\mu \mathrm{m}$ theoretical spatial resolution results in a resolution of $13.9 \mu \mathrm{m}$. Systematic errors such as a slightly defocused CCD and crystal mosaic effects combine to further lower the resolution.

The absolute yield of $K \alpha$ photons was measured using a single hit CCD spectrometer and the spatially resolved absolute brightness of the source was determined by comparing the integrated counts in the images of the source with the absolute number of photons. Details of the absolute $K \alpha$ measurement are discussed elsewhere. ${ }^{7}$ The source brightness was $4.2 \times 10^{13}$ photons $\mathrm{cm}^{-2} \mathrm{sr}^{-1}$ and the collection angle of the imaging diagnostic is $4.4 \times 10^{3} \mathrm{sr}$. Very high temporal resolution of $\sim 1$ ps resulted from the 800 -fs pulse in the backlighting beam. 5 Various phases of implosion were imaged by delaying the backlighting beam with respect to the driver beams. The timing was jitter-free since the long pulse implosion drive was obtained by further stretching and amplification of a fraction of the uncompressed chirped pulse. ${ }^{6}$ Figure 1(a) shows a backlit image of an unirradiated shell. Limb darkening is clearly seen together with a glue blob attaching the support fiber. The limb transmission minimum was measured from the line out in Fig. 1(b) to be $85 \%$. A theoretical transmission profile of the 500- $\mu \mathrm{m}$-diam, 7 - $\mu \mathrm{m}$-thick shell yielded a transmission minimum of $75 \%$. The effect of finite resolution was determined by convolving this theoretical profile with a Gaussian kernel. The calculation uses shell density and opacity of $1.03 \mathrm{~g} / \mathrm{cm}^{3}$ and
FIG. 2. (a) $K \alpha$ radiographic image of a polymer shell at peak compression. (b) The vertical line out [indicated by the vertical line through the image 2(a)] shows the fully compressed core. Also shown is the range of interpolated backlighter intensities used in the density calculations.

$23 \mathrm{~cm}^{2} / \mathrm{g}$, respectively. Adjustment of the FWHM of the Gaussian to match the $85 \%$ observed minimum yields an effective resolution of $20 \mu \mathrm{m}$.

The image has a maximum counts per pixel of 18000 . With $\sim 22 \mathrm{eV} /$ count and $4.5 \mathrm{keV}$ photons, this corresponds to an average of $\sim 81$ photons/pixel or a signal to noise $(\mathrm{S} / \mathrm{N})$ ratio of $\sim 9: 1$ in the raw images. Smoothing of the image into $3 \times 3$ pixel areas enlarges the region over which the statistical count is made resulting in the observed $\mathrm{S} / \mathrm{N}$ ratio of about 27:1 as shown in Fig. 1(b). A shell at maximum compression ( $3.25 \mathrm{~ns}$ after drive peak) is shown in Fig. 2(a). Here the backlighter source size has been increased to $420 \times 750 \mu \mathrm{m}^{2}$ and the peak brightness is reduced to 5.2 $\times 10^{13}$ photons $\mathrm{cm}^{-2} \mathrm{sr}^{-1}$. In Fig. 2(b), a line out of the implosion core absorption pattern reveals a $96-\mu \mathrm{m}$ diam FWHM. A similar image of an implosion incorporating at $30^{\circ} \mathrm{Au}$ cone positioned with the cone axis $51^{\circ}$ from the radiographic axis is shown in Fig. 3. The FHWM core diamwith a $40-\mu \mathrm{m}$ outer diam. The opening angle appears significantly larger than $30^{\circ}$ due partly to the $51^{\circ}$ viewing angle, which increases the apparent angle to $38.4^{\circ}$. The much higher observed angle of $85^{\circ}$ indicates an additional increase

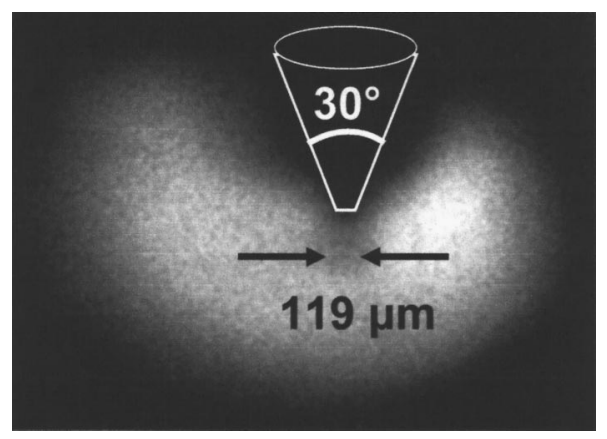

FIG. 3. Cone implosion radiograph at $3.25 \mathrm{~ns}$ after the drive peak shows a $119-\mu$ m-diam stagnated core near the tip of a $30^{\circ} \mathrm{Au}$ cone. The outline indicates the $51^{\circ}$ oblique view. eter is $119 \mu \mathrm{m}$. The tip face of the cone is $5 \pm 2 \mu \mathrm{m}$ thick 

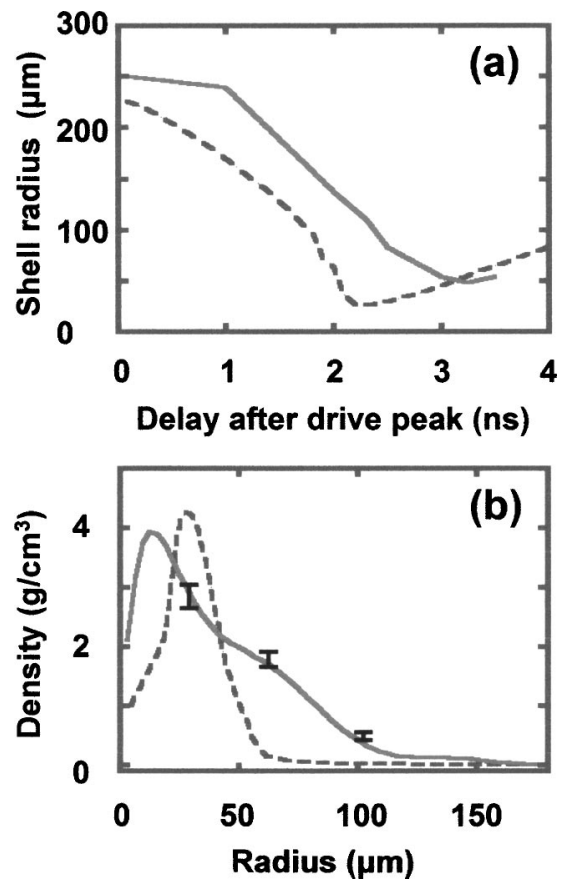

FIG. 4. (a) Shows the shell radius as a function of time after drive peak and (b) indicates the core density as a function of radius at peak compression. The solid lines are experimentally obtained and the dotted lines are results of the 1D HYDRA code.

attributable to ablation of $\mathrm{Au}$ from the cone by thermal $\mathrm{x}$ rays. ${ }^{10}$

Images from a sequence of timings show a smooth implosion from a 500- $\mu \mathrm{m}$ shell through the $96-\mu \mathrm{m}$ stagnation at $3.25 \mathrm{~ns}$, followed by expansion to $104 \mu \mathrm{m}$ at $3.5 \mathrm{~ns}$. Diameters are defined as the FWHM of attenuation. Measurement error was determined by the $20-\mu \mathrm{m}$ resolution, which increases the apparent diameter, combined with $27: 1 \mathrm{~S} / \mathrm{N}$, which contributes a random error. The shell diameter versus the short pulse delay reveals an average implosion velocity of $6.0 \times 10^{4} \mathrm{~m} / \mathrm{s}$. We have compared our results to onedimensional (1D) simulations using HYDRA $^{11}$ of a 7 - $\mu$ m-thick $500-\mu$ m-diam plastic shell with a low density $\left(1 \times 10^{-5} \mathrm{~g} / \mathrm{cm}^{3}\right)$ gas fill irradiated by a 1.0 -ns 800 -J Gaussian laser pulse. To simulate the effect of hot-electron preheat we directly deposited energy into the shell. With $5 \mathrm{~J}$ of absorbed preheat we find a peak implosion velocity of 7.0 $\times 10^{4} \mathrm{~m} / \mathrm{s}$ and an $80-\mu \mathrm{m}$-diam stagnated core $2.5 \mathrm{~ns}$ after the peak of the pulse. The modeled implosion trajectory is co-plotted with the observed trajectory in Fig. 4(a). The 17\% shorter time to peak compression in the model indicates that the $1 \mathrm{D}$ approximation of a range of ray directions used to represent the six-beam tangential overlap of the drive beams, overestimates the drive.

The opacity of the imploded shell is a function of its temperature and density. Data from the Sesame tabulations show that over an expected range of temperature and density, the opacity for $4.6 \mathrm{keV}$ radiation is approximately invariant at $43 \mathrm{~cm}^{2} \mathrm{~g}^{-1}$. Intensity line outs of implosion cores were processed to obtain transmission profiles by comparison to unattenuated intensity profiles. The form of the unattenuated profiles was determined to be nearly Gaussian. Shot-to-shot profile estimations were based on an interpolated fit to the backlighter line out [Fig. 2(b)]. This transmission data was Abel inverted to obtain a density profile as shown in Fig. 4(b). As an estimate of the calculated density error, multiple inversions were performed for various backlighter profiles within the range of their uncertainty [Fig. 2(b)]. The peak compression density rises quasilinearly from the zero density edge to $4 \pm 0.25 \mathrm{~g} / \mathrm{cm}^{3}$. Also shown in Fig. $4(\mathrm{~b})$ is the HYDRA-predicted density profile (with $5 \mathrm{~J}$ of preheat) at maximum compression showing a peak density of $3.75 \mathrm{~g} / \mathrm{cm}^{3}$ (compared to $45 \mathrm{~g} / \mathrm{cm}^{3}$ without preheat).

In conclusion, it has been demonstrated that ultraintense laser-driven Ti $K \alpha$ monochromatic backlighting and imaging is a viable radiographic diagnostic for characterization of laser driven implosions.

This work was performed under the auspices of the U.S. Department of Energy by the University of California Lawrence Livermore National Laboratory under Contract No. W-7405-Eng-48. We acknowledge R. Clarke, M. Notley, R. Heathcote, D. Neville, P. Brummitt, M. Tolley and D. Neely for their technical support of the experiment.

${ }^{1}$ M. H. Key, C. L. S. Lewis, J. G. Lunney, A. Moore, T. A. Hall, and R. G. Evans, Phys. Rev. Lett. 41, 1487 (1978).

${ }^{2}$ M. H. Key, C. L. S. Lewis, L. Cooke, J. M. Ward, R. G. Evans, and P. T. Rumsby, Phys. Rev. Lett. 45, 1801 (1980).

${ }^{3}$ P. T. Rumsby, M. H. Key, C. J. Hooker, A. J. Cole, J. D. Kilkenny, and R. G. Evans, Nature (London) 299, 329 (1982).

${ }^{4}$ R. L. Kauffman, Physics of Laser Plasma, edited by A. Rubenchik and S. Witkowski (North-Holland, Amsterdam, 1991), pp. 111-162.

${ }^{5}$ C. Reich, P. Gibbon, I. Uschmann, and E. Forster, Phys. Rev. Lett. 84, 4846 (2000)

${ }^{6}$ P. A. Norreys, K. L. Lancaster, C. D. Murphy, H. Habara, S. Karsch, R. J. Clarke, J. L. Collier, R. Heathcote, C. Hernandez-Gomez, S. J. Hawkes, D. Neely, M. H. R. Hutchinson, R. G. Evans, M. Zepf, J. A. King, R. Freeman, S. Hatchett, M. H. Key, R. Stephens, C. Stoeckl, K. A. Tanaka, T. Norimatsu, Y. Toyama, and R. Kodama, Central Laser Facility Annual Report 2002/2003 (unpublished), pp. 35-39.

${ }^{7}$ J. A. King, M. H. Key, C. D. Chen, R. R. Freeman, T. Phillips, K. Akli, M. Borghesi, M. Chen, R. Clarke, T. Cowan, H. Habara, S. Hatchett, R. Heathcote, S. Karsch, J. A. Koch, R. Kodama, K. L. Lancaster, A. MacKinnon, C. D. Murphy, P. Norreys, P. Patel, L. Romagnani, R. Snavely, R. Stephens, C. Stoeckl, R. Town, Y. Toyama, M. Zepf, B. Zhang (unpublished).

${ }^{8}$ R. Kodama, H. Shiraga, K. Shigemori, Y. Toyama, S. Fujioka, H. Azechi, H. Fujita, H. Habara, T. Hall, Y. Izawa, T. Jitsuno, Y. Kitigawa, K. M. Krushelnick, K. L. Lancaster, K. Mima, K. Nagai, M. Nakai, H. Nishimura, T. Norimatsu, P. A. Norreys, S. Sakabe, K. A. Tanaka, A. Youssef, M. Zepf, T. Yamanaka, Nature (London) 418, 933 (2002).

${ }^{9}$ J. A. Koch, Y. Aglitskiy, C. Brown, T. Cowan, R. Freeman, S. Hatchett, G. Holland, M. Key, A. MacKinnon, J. Seely, R. Snavely, and R. Stephens, Rev. Sci. Instrum. 74, 2130 (2003).

${ }^{10}$ R. B. Stephens, S. P. Hatchett, R. E. Turner, K. A. Tanaka, R. Kodama, Phys. Rev. Lett. 91, 185001 (2003).

${ }^{11}$ M. Marinek, S. W. Haan, T. R. Dittrich, R. E. Tipton, G. B. Zimmerman, Phys. Plasmas 5, 1125 (1998). 